\title{
Parents living with a child afflicted by a life-limiting medical condition: Typology of their narrative identity
}

\author{
Sylvie Lafrenaye, ${ }^{1,2}$ Marc Dumas, ${ }^{3}$ Émilie Gosselin, ${ }^{5}$ André Duhamel, ${ }^{4}$ Patricia Bourgault ${ }^{5}$ \\ ${ }^{1}$ Department of Pediatrics, University of Sherbrooke, Sherbrooke; ${ }^{2}$ Center for Clinical Research of the Sherbrooke University Hospital, \\ Sherbrooke; ${ }^{3}$ Center of Contemporary Religious Studies, University of Sherbrooke; ${ }^{4}$ Department of Philosophy and Applied Ethics, \\ Faculty of Letters and Human Sciences University of Sherbrooke; ${ }^{5}$ School of Nursing Sciences, Faculty of Medicine and Health Studies, \\ University of Sherbrooke, Québec, Canada
}

\begin{abstract}
Parents of children suffering from a life-limiting medical condition struggle with difficult existential questions. Our objective was to understand why those parents' interactions with the medical world were so different, ranging from hostile to collaborative, with the themes of identity, spirituality and serenity. A grounded theory design based on the narrative identity framework was used to interview sixteen parents. Three categories emerged: i) Parents in the Almighty category delegate all their power to God or medicine and are the most suffering parents as they do not author their life; ii) Parents in the Me category make every decision on their own causing much anxiety, and they become rebarbative to the medical world; iii) Parents in the Guide category take advice from others, while remaining the authors of their stories and are the most serene parents. Understanding and recognizing these categories can have a major impact on communication with those families.
\end{abstract}

Correspondence: Sylvie Lafrenaye, Department of Pediatrics, University of Sherbrooke, 3001-12 Avenue Nord, Sherbrooke (Québec), Canada, J1H 5N4.

Tel.: 819.346.1110 ext. 74634.

E-mail: Sylvie.Lafrenaye@USherbrooke.ca

Key words: Parents; children; life-limiting medical condition; serenity; interviews; qualitative analysis.

Conflict of interest: The authors declare no conflict of interest.

Availability of data and materials: All data generated or analyzed during this study are included in this published article.

Ethics approval and consent to participate: The Ethics Committee of the CR-CHUS (Centre de Recherche du Centre Hospitalier Universitaire de Sherbrooke) approved this study (no 09-085-R1). The study is conformed with the Helsinki Declaration of 1964, as revised in 2013, concerning human and animal rights. All patients participating in this study signed a written informed consent form for participating in this study.

Informed consent: Written informed consent was obtained from a legally authorized representative(s) for anonymized patient information to be published in this article.

Received for publication: 10 June 2020.

Accepted for publication: 1 April 2021.

This work is licensed under a Creative Commons Attribution NonCommercial 4.0 License (CC BY-NC 4.0).

${ }^{\circ}$ Copyright: the Author(s), 2021

Licensee PAGEPress, Italy

Qualitative Research in Medicine \& Healthcare 2021; 5:9174

doi:10.4081/qrmh.2021.9174

\section{Introduction}

Parents of children suffering from a life-limiting medical condition struggle with difficult questions as they search for meaning in their life, ${ }^{1}$ and this inevitably emerges during medical visits. Some parents are serene and collaborate with healthcare providers, whereas others are unpleasant and reluctant. ${ }^{2,3}$ In some cases, these negative relationships with the medical community can adversely affect the precarious health of the child. These parents find themselves at the crossroads between curative and palliative care, in a "psychological limbo", ${ }^{4}$ with the death of their child expected within months or years to come. The existential ambivalence between providing care and letting go is always present for the parents, as well as for the medical caregivers. These children are supported by their parents and the healthcare providers to live as best as possible (palliative care), while also preparing for their death. ${ }^{5}$ The parents have to contemplate soulsearching questions concerning their own identity, ${ }^{1,6,7}$ and their role as someone responsible for themselves and for a life that depends on them. ${ }^{8}$ Questions of meaning and of "why me?" inevitably arise. ${ }^{5}$ Medical science is interested in the "how?" of the disease (biological and genetic explanations), while parents wonder about the "why?". Unfortunately, too often the discourses on the "how" and the "why" do not overlap."

It is believed that the spiritual dimension of the parents' experience may play a role in the resolution or attenuation of the suffering of those parents. ${ }^{5,10,11}$ Spirituality, a complex concept to synthesize, usually includes aspects of meaning, beliefs, self-transcendence, connections and values. For this study, we were interested 
mainly in the identity-integrity aspect of spirituality. Hence, we defined (and limited) spirituality as self-realization and the realization of an existential project mediated by the search for meaning. ${ }^{12}$ The concept of identity has many definitions. It can be understood as personal, cultural, professional, psychological, etc. The narrative model of identity provides an inclusive and exhaustive account of identity. It gives an irreducible role to the firstperson perspective, unique to everyone. Narrative identity is also dynamic and intersubjective. It provides the individual with a sense of unity and purpose in life.

Paul Ricœur suggested a theoretical framework of narrative identity. ${ }^{13}$ Identity is divided into two notions: "who am I?" (ipse) and "what am I?" (idem). Ricoeur defines the "what am I?" as what we retain to remind ourselves of who we are as we age and as time passes. ${ }^{13}$ In contrast, the "who am I?" is more difficult to grasp. The ipse identity is constructed through negotiation, as well as links and relationships with others. This is expressed by the promise we make to others, and this defines us. According to Ricoeur, this identity that we build from our life narrative ensures the cohesion of our lives. ${ }^{13}$ When illness arises in one's life, a change in narrative takes place. Individuals form a narrative identity by integrating their life experiences into an internalized, evolving story of their self. The life narrative integrates one's reconstructed past, perceived present, and imagined future. Several authors discuss the experience of a chronic illness as a biographical disruption or rupture. ${ }^{14,15}$ Then, biographical work is done to construct the resolution of suffering associated with the presence of the illness in our life. ${ }^{16}$ As we choose the aspects of self-realization and the realization of an existential project as our main theme of spirituality, we amalgamate the concepts of the search of meaning, identity and achievement of a life project into the construction of the concept of spiritual identity.

Following the chaos of diagnosis, ${ }^{1}$ parents either find meaning in what they are experiencing (possibly to decrease their suffering), or due to a lack of finding a purposeful meaning, their existential suffering persists. ${ }^{5}$ This construction of meaning is a process and an inner journey that comprised of several elements, including spiritual identity, moral values, priorities, and beliefs. From this inner journey, serenity may arise. This serenity, or lack of it, should be noticeable during medical encounters. ${ }^{17} \mathrm{We}$ define serenity as a state or quality of being serene, calm, or tranquil, and a spiritual experience of inner peace that is independent of external events. ${ }^{18}$

Why is serenity so important? A lack of parents' serenity is often felt by those involved in the care of their child. This in turn may hinder the parent-healthcare provider collaboration that is so essential for the welfare of children suffering from a life-limiting medical condition. ${ }^{2}$ However, little is known about the associated effect of spiritual identity and serenity on parents' interaction with the medical world. A better understanding of this effect could allow caregivers to provide tailored support to parents of life-limited children.

\section{Materials and Methods}

\section{Aim}

The goal of this study was to understand why interactions with the medical world were so different among parents of life-limited children, ranging from hostile to collaborative, from anxious to serene. We explored how the theme of spiritual identity could be linked to their state of serenity, or said otherwise, to their state of suffering.

\section{Design}

We used a qualitative study design based on a constructivist approach. As our objective was to understand the links between the concerns, the actions, and the narratives of a group, in this case, parents of children with life-limiting disease, we opted for a grounded theory design. ${ }^{19}$ In this approach, when a person lives in a social situation, he or she is the only one who can construct and give meaning to his or her behaviour. ${ }^{20}$

\section{Participants}

Recruitment was limited to parents of children with lifelimiting disease, with life expectancy of less than 20 years old. Recruitment was completed through references by specialized clinical nurses and pediatricians who were caring for such sick children, after publicising our study. In our cohort, the children suffered from severe neonatal neurological conditions, severe hypotonia of unknown cause, neurodegenerative diseases, and congenital diseases. To be included in this study, the parents of the sick child had to live together, be in stable economic condition and willing to share their thoughts about living with a sick child. These decisions were made to avoid data contamination by financial worries, which are common in many single-parent families caring for a child with chronic illness. ${ }^{21,22}$ Participants known by the interviewer were excluded to avoid bias. All participants were French speaking. Participants were recruited until data and category saturation were reached. Data saturation was reached after eight couples were interviewed, meaning eight fathers and eight mothers participated.

\section{Procedure and data collection}

Two in-depth interviews, at least two months apart, at the parents' home allowed parent-researcher co-constructions of data. All interviews, conducted by an experienced pediatric intensivist, were audiotaped and transcribed, after consent forms were signed. The fact that the researcher was a physician, well aware of the signs and symptoms of most of the children's diagnoses, allowed for the themes of the study to emerge more rapidly, without losing time in explaining the treatment and care pro- 
cedures for each of the children. Interview guides were prepared by the research committee and evolved throughout the study to get the most in-depth responses. Data collection and data analysis were conducted simultaneously in an iterative manner.

The first semi-structured, in-depth interview was done with both parents together. Parents were asked to talk about several aspects of the situation: the experience of their life while living with their sick child, and the emotional turmoil that results, how they would change something in their life, "Why me?" and their appreciation of their relationship with the medical world. A phenomenological analysis of their story was completed after the first encounter to produce a literary narrative.

During the second interview, this literary narrative produced from the previous interview and printed in a booklet was read to them. ${ }^{23}$ This approach ensured the accuracy of the comments gathered during the first interview and allowed the parents to feel understood, involved and acknowledged. Parents were invited to comment or change the narratives after the narratives were read to them. None of the 16 parents made any comments on their narrative. All the parents kept the booklet; however, they were all more interested in continuing to unfold their stories. The second sets of interviews were held individually, with each parent being questioned separately to allow in-depth discussion surrounding the themes of spirituality and identity. The interview guide then included questions about what aspect of the interactions was the most helpful and about parents' definition of "spirituality." They were also asked how they imagine their answer would be different 10,20, or 30 years from now, as spirituality is linked to the concept of self-realization. Most specifically, parents were asked to define themselves by answering "Who am I?". At least two months separated the two encounters to allow a more comprehensive view of their lived experiences.

During the interviews, the researcher captured the ambiance, atmosphere and serenity of the household and parents by paying attention to their words, gestures, attitude, welcoming moments, and feeling of the encounter. Serenity, as opposed to a state of suffering (a state in which chaos, anger or lack of understanding are prevalent), ${ }^{18}$ was palpable during the interviews. In this context, we assumed that being serene is a state felt both at home and during medical visits, and this would have to be recognized in their interactions with the medical world. No serenity or suffering numeric scales were used to avoid parents to be restrained and influenced by a numeric answering questionnaire, as this project takes place in a constructivist approach, and also to avoid social desirability.

\section{Ethical considerations}

This study was approved by the local research ethics committee. Recruitment was carried out through pediatricians and staff nurses at the CHUS (Sherbrooke University Hospital). Parents were told that this research was investigating how to live with a sick child, but they were not aware of the serenity and spirituality aspect of the study to avoid bias and changes in their attitude. Parents' quotes were identified by a code, including $\mathrm{M}$ or $\mathrm{F}$ for the mother or the father, and 1 or 2 for the first or second interview to ensure anonymity. During the analysis, the child's given name was modified to assure confidentiality and to avoid recognition. Participation was voluntary and parents could withdraw at any time.

\section{Data analysis}

Interviews were transcribed verbatim to be used for analysis. Quotes presented in this paper are free translations. Open coding was done using the Qualitative Data Analysis Miner software (QDAminer, Provalis Research, Montreal, Canada) by members of the research committee to obtain inter-rater agreement. Triangulation (of theory, data, and observers) was carried out subsequently. ${ }^{19}$ Then, categorization of data took place. Parents' transcribed interviews were interpreted considering the theoretical framework of narrative identity of Paul Ricœur and our concept of spiritual identity. ${ }^{13}$ According to the approach described by Paillé and Muchielli, data were also interpreted in the context of parents' serenity, seen as a continuum. ${ }^{24}$ Hence, the parents were classified into three groups: not serene, moderately serene, and serene, assessed subjectively by the researcher during the interview and by the content of the transcripts. This categorization was inversely proportional to their suffering that was expressed by complaints, anger, tears, and especially the chaos of their life so far, either now or later on in their life.

\section{Results}

Eight fathers and eight mothers of eight children were recruited. The children of these parents were aged between three and eight years old, with life expectancies of less than 20 years. We gathered 26 hours of interviews and collected over 800 pages of verbatim transcripts out of 24 interviews ( 8 couples, 16 individuals). An overview of the participants included in the present study is shown in Table 1.

\section{Typology of parents in three categories}

Data analysis led us to a typology of three categories: i) Almighty, ii) $M e$, and iii) Guide. These categories are not clear-cut and may change for different aspects of their life. The categorization was not dichotomous, rather a continuum of their spiritual identity in the context of their life with a sick child (Figure 1).

The Almighty category is represented by a parent delegating his or her power to the Other, whether that be God or science or medicine. Parents in the Almighty category trust the Other absolutely, to the point where they do not feel they are the authors or masters of their story, they are only actors. Either they did not want to author the script 
of their experience or they were too shocked to be able to do so. For example, one mother said: "Do we get angry at Him, do we rebel? In this case, we're all alone or, instead, He knows everything, He has an explanation for this, which we may never know." (Mam2).

The $M e$ category is at the opposite end of the spectrum. Parents in the $\mathrm{Me}$ category were proud to say that they are self-made and autonomous, that they do not rely on anyone and that they decide everything on their own. These parents carry a heavy burden on their shoulders: "[Do you believe in a higher power, a God, a guide who protects?] No, absolutely not... I would say that it's me... I want to run my life, I'm in charge." (Mem1). These parents are under tremendous stress and have difficulty imagining the future. The serenity of the $M e$ parents is compromised by the stress they put on themselves, now and in the future to "save" their child from the medical world that they don't trust: "we can't rely on others" (Naf2).
The Guide category was somewhere in between trusting completely and only the Other or trusting completely and only themselves regarding the care to give to their child. Parents in the Guide category listen and take advice from others, but remain the authors of their own stories and choices. They were serene and hence, allowed themselves to listen to the health professionals, while remaining confident in their decisions for their child. They allowed themselves to be guided, while maintaining their identities. "They're just tools that he [a psychologist] gave us to fill our toolbox. That's made us come back together as a couple. It's us that came back together, and then it's us who made it possible." (Mim1). They expressed freedom in the choices they make of their life "I was going to make the hyperbaric chamber, [the doctors] were against it. ... so I learned what? To lie to them because they were never open to what I could live" (Mim1). They felt free to learn: "I have a drive to know, to learn [life] ... to infinity " (Mif2).

Table 1. Characteristics of the children. Hospital stay represents the number of time the child has been hospitalized. Pain was assessed by the parents in relation to the medical conditions per se. Medical conditions were: i) severe neonatal neurological conditions, ii) severe hypotonia of unknown cause, iii) neurodegenerative diseases, and iv) congenital diseases.

\begin{tabular}{|c|c|c|c|c|c|c|c|c|}
\hline Child & 1 & 2 & 3 & 4 & 5 & 6 & 7 & 8 \\
\hline Sibling rank & $2 / 3$ & $2 / 2$ & $4 / 4$ & $1 / 1$ & $1 / 1$ & $2 / 2$ & $1 / 1$ & $3 / 3$ \\
\hline Gender & $\mathrm{F}$ & $\mathrm{F}$ & $\mathrm{F}$ & M & $\mathrm{F}$ & M & $\mathrm{F}$ & $\mathrm{F}$ \\
\hline Age (years) & 5 & 4 & 8 & 4 & 3 & 6 & 8 & 8 \\
\hline Hospital stay & + & +++ & & ++ & ++ & ++ & + & + \\
\hline Pain $(0-100)$ & 50 & 90 & 5 & 30 & 95 & 80 & 5 & 20 \\
\hline Medical condition & 1 & 3 & 2 & 3 & 4 & 3 & 1 & 2 \\
\hline Cognitive impairment & +++ & + & +++ & ++++ & + & ++++ & + & ++ \\
\hline
\end{tabular}
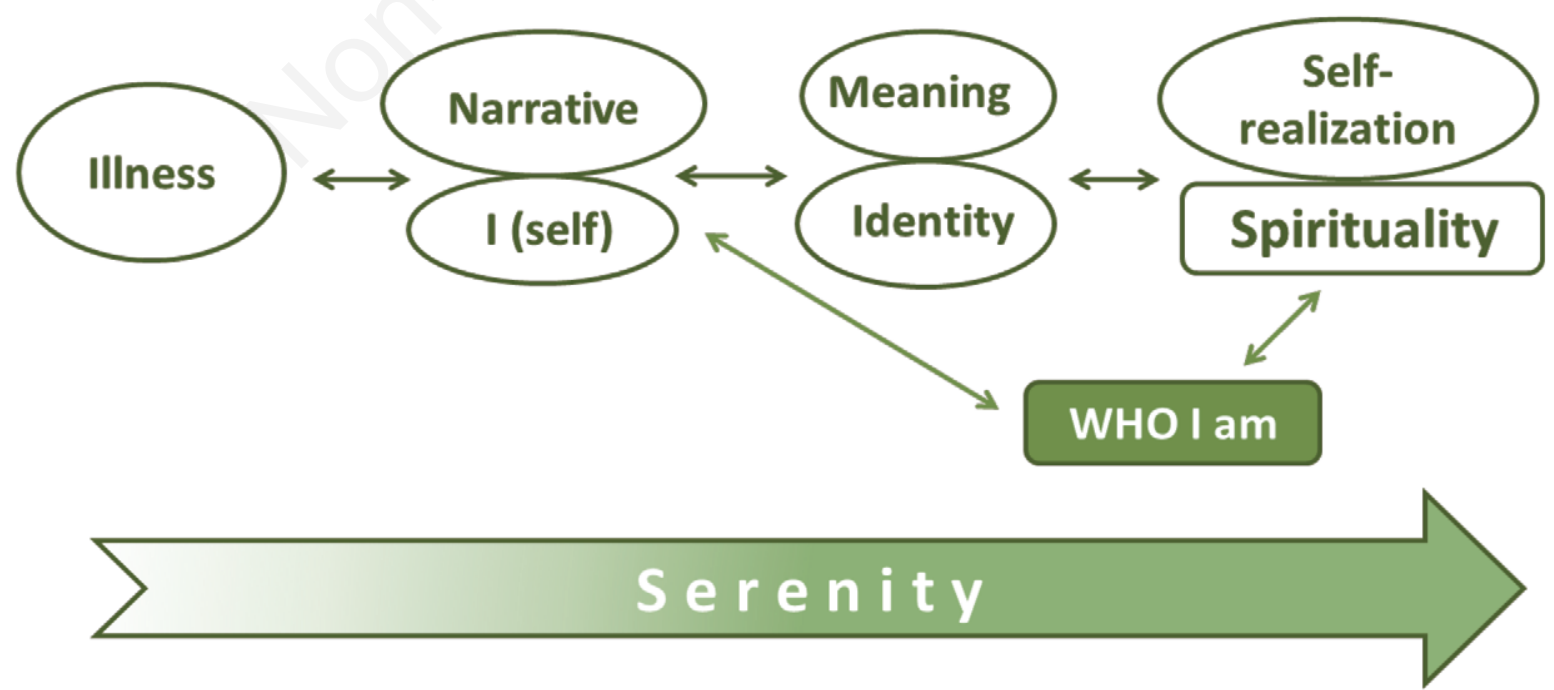

Figure 1. Co-construction of conceptual framework with parents and researchers. The conceptual framework includes the concepts of Ricoeur's narrative identity and the restricted aspect of spirituality retained in this study which is self-realization. In summary, the child's illness leads to a narrative done as a subject by the parents. This expression helps to find meaning and imbricate the parent's identity which will move (or not) with time to self-realization. 


\section{Spiritual identity}

As we decide to restrict the complex concept of spirituality to the person's self-realization, a concept linked to growth, progress, plan or difference for the future, we chose to add questions about how the parents would imagine themselves in years to come. The main factor linked to serenity of the parents was the recognition and establishment of a spiritual identity (Figure 2). This was especially apparent when analyzing their answers regarding their projection of the future: would they want to be the same or would they want to evolve into a different person? The most serene parents were looking into the future with confidence and peace, hoping to see themselves more conscious of their affective and interpersonal potential. "I will be different, I will evolve" (Mom2); "I want to calm down, but I want to keep my spark" (Sem2). Serenity was felt to be subjectively comparable for both visits (months apart) for every family.

Defining themselves (Who am I?) was quite difficult for most (15 of the 16) parents. Only one mother was able to easily answer. She was the most serene parent observed in the group. She is an example of the concept of serenity: "When he is sick, and it's not going well, I always give him the choice: "If you want to go, Mommy will let you go. But if you want to stay, I'll be very happy." Because, for me, my little boy is not a burden... It might not be easy when he'll be ready to go, but I'd do things the same way if I had to do it again." (Mom2).

For the parents in the Almighty category, they did not have a concrete answer to the question: "Who am I?": "It's a very tough question because who I am... This one doesn't come easily. Basically, I don't know. That's the answer. I don't know myself... I don't know who I am" (Maf2). These parents tend to conceive themselves as medical technicians more than as parents. For one mother, who sincerely trusted medical professionals, the following statement is very revealing:" [A therapist told her]: "You're going to give up your role as a therapist... you're just doing your role as a mother" ... The homework she gave me this week was to take [my daughter] in my arms. ...I haven't done it yet this week. ...It always annoyed me to give her a bath. I'm lucky because now it's caregivers who do it... Physical contact, I'm not able to do that yet" (Mam2). This mother had turned everything over to medical professionals. This mother and her husband were considered exceptional parents by the therapists; they respected all prescribed exercises in a remarkable manner during the first years of life of their child. These parents believed that if they listened to the medical authority, their child would return to normal. However, this did not happen. They were devastated and did not know "who" they were anymore.

Parents in the $M e$ category can define themselves in the present, but projecting themselves in the future is a harder task, almost impossible. Since all responsibilities and decisions remain solely on their shoulders, they are exhausted and do not want to think about tomorrow, either for their child or for themselves. "Physically, I think this is making us age a lot.... It creates stress... the condition of [my daughter] forces us to make decisions that make me feel under much pressure ... we can't rely on others... all choices are on our self" (Naf2). For these parents, the expression "living for today" or "one day at a time" does not indicate a Zen mentality. It seems to seems to be an escape from having to think about tomorrow, because this is too terrifying and distressing. "On this point, I have not changed much, for 20 years ... I'm fine" (Rof2). They don't look at changing or evolving as individuals, as life is so rough.

Parents in the Guide category define themselves simply: "I am a person similar to everyone else. I have a dark side and a light side, but I'm very optimistic. ...in my heart, I'm still 10 years old, I'm rolling in the snow out-

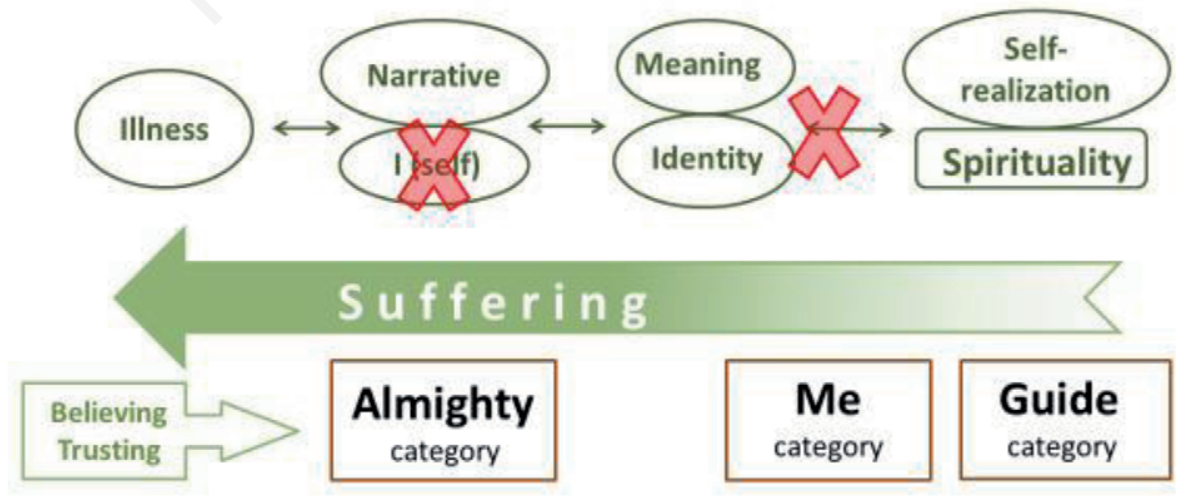

Figure 2. Typology of parents' spiritual identity. The parents' narrative analysis lead to three groups for spiritual identity: the parents in the Almighty group give all control to the Other (Medicine or God) and do not act as author of their life. The Parents in the Me group put all the decisions on their own shoulders. Despite a strong identity, they are unable to project themselves in the future because of tiredness. Parents in the Guide group felt guided by the Other but keep authorship for decisions concerning their child. Parents' suffering was linked to these categories. 
side... I think life is beautiful." (Mom2). For these parents, projecting themselves into the future is neither difficult nor distressing. To the question, "who will you be in 10 or 20 years from now?" they answered in a serene fashion: "I hope I have grown. I like to learn... I hope that in 20 or 30 years that I will have experienced many things... I hope I will have grown enough to be above many things" (Mim2). When they think about the future, they see themselves as transformed. "Being present, but in my body, but also in my soul, then laughing at it, “... (Sem1)

\section{Summary of results}

Parents were categorized according to the analyses of all verbatim transcripts (Figure 3). The main factor linked with the serenity of the parents was the establishment/ recognition (or not) of a spiritual identity, or said otherwise, a narrative self-realization, now and in the future. Parents in the Almighty category do not see themselves as the authors of their own stories, thus undermining their spiritual identities and the meaning they give to their lives with their sick child. Parents in the $M e$ category are quite serene in the present and are able to define themselves, but they have difficulty imagining their future; self-realization requires the energy to look further than the present moment. Parents in the Guide category are the most serene; they are able to spiritually define themselves and can serenely imagine their future.

\section{Discussion}

Our objective was to understand why interactions of parents of children suffering from a life-limiting medical condition with the medical world were so different, ranging from hostile to collaborative, from anxious to serene. We worked with the themes of identity, spirituality, and serenity. A grounded theory design was used to interview sixteen parents. Our objective was to explore how the parents' spiritual identity (defined as self-realization) could be linked to serenity while caring for a child with an incurable disease. A typology correlating this association emerged from our study.

To be a parent is to be a person. As the parents' narrative is a story with a beginning, a middle and a potential finale, the actual story of their life with their sick child was coconstructed with the main researcher. The life narrative is presumed to provide a sense of unity and purpose in life. As our concept of spiritual identity is linked to self-realization, the parents' narratives were used as a proxy to understand their relationships with the medical world.

Our typology is reminiscent of those on the role of narratives in the resolution of suffering associated with chronic illness, previously reported in the literature (Table 2). The Almighty category is comparable to the Restitution, ${ }^{16}$ Accommodation, ${ }^{8}$ Stable,${ }^{25}$ Trapped ${ }^{26}$ the constant and the invalid classifications, ${ }^{27}$ proposed by different authors. The $\mathrm{Me}$ category is reminiscent of the Chaos, ${ }^{16} \mathrm{Re}-$
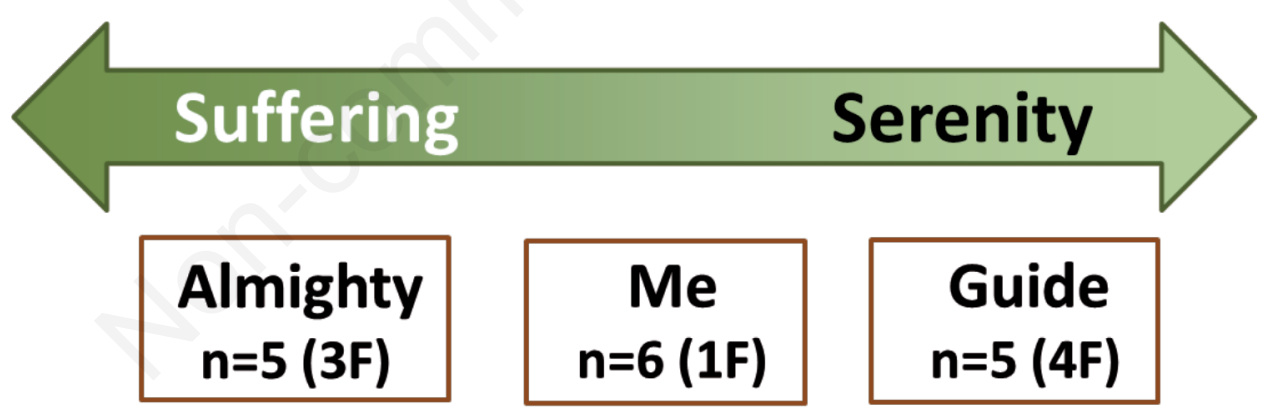

Figure 3. Results of typology per parents' category. The typology in three groups linked parents to either serenity or suffering. The 16 parents are divided almost equally amongst the groups. The number $\mathbf{F}$ in parenthesis represent the number of females (mothers).

Table 2. Comparison with other typologies.

\begin{tabular}{lccc}
\hline Lafrenaye (2020) & Almighty & Me & Guide \\
\hline Frank (2013) & Restitution & Chaos & Quest \\
\hline Gray (2001) & Accommodation & Resistance & Transcendence \\
\hline Robinson (1990) & Stable & Regressive & Progressive \\
\hline Nicholas (1999) & Trapped & Embedded & Adaptative \\
\hline Meldrum (2009) & Constant patient and invalid & Weary soldier and decision maker & Stoic and postive thinker \\
\hline Bray (2014) & Continuity & Disruption & Enrichment
\end{tabular}


sistance, ${ }^{8}$ Regressive ${ }^{25}$ Embedded, ${ }^{26}$ the weary soldier and the decision-maker, ${ }^{27}$ as described by the authors of these studies. The Guide category is similar to Quest, ${ }^{16}$ Transcendence, ${ }^{8}$ Progressive, ${ }^{25}$ Adaptive, ${ }^{26}$ the stoic and the positive thinker. ${ }^{27}$ The authors of those studies used different research designs, but their typologies include three categories, similar to the ones described in the present study. After six studies, these classifications could be considered empirically sound.

Our categorizations of the parents' decisions related to the medical world could also be described by 'Heteroautonomy-Closed autonomy-Open autonomy.' Parents in the Almighty category show a hetero-autonomy, as they are obedient and dependent upon medical caregivers to make all the decisions about care of their sick child. By contrast, parents in the $M e$ category show closed autonomy, as they decide everything on their own without taking advice from others - including medical caregivers. Parents in the Guide category could be described as open autonomy, as they neither turn decision-making completely over to medical caregivers nor take the burden of decision-making solely upon themselves.

Our study allows an additional explanatory element, which is that of the role of spiritual identity. Living with a sick child who will die before the parents is disturbing, challenging, and requires great selflessness. Existential questioning keeps coming back to the parents' minds. The relationship to the Other/other is central. Spirituality leads to the question of the Other and the other. The Other being the transcendent entity that oversees our lives, whether that entity be God, the cosmos or universal intelligence. ${ }^{28}$ The "other" is the term for the people circulating around the parents. The quality of the link to the other or the Other leads to the construction of a robust identity, allowing an inner freedom, a freedom that the parents in the Almighty category do not reflect. ${ }^{29}$ They are prisoners (opposite to freedom) of the medical world, becoming therapists, and not parents, for their child. ${ }^{30}$ They are not serene because their child was not "cured," as they thought would happen with their good therapists' care. They are disappointed, distressed, and sad. The Me parents do not trust anyone for their decisions concerning their child. Their overwhelming freedom locks them, the other could never be a rescue. ${ }^{7}$ Their overall relationships are challenged or compromised. ${ }^{6,7}$

The meeting point of spiritual and serenity concepts is found in the ideas of evolution and transformation, as expressed by the parents in the Guide group. Serenity, characterized by its qualities of freedom, fluidity, calm, and comfort, includes as does the concept of spirituality, a relationship to the Other/other, now and in times to come. Indeed, the two scales found in the medical literature measuring serenity suggest that serenity is an intrinsic component of spirituality. ${ }^{18}$ Kreitzer concludes that the serenity scale captures a state of acceptance, peace, and an inner confidence, distinct from the elements sought by scales exclusively for spirituality. ${ }^{18}$ Kruse suggests that serenity is the "human becoming perspective." ${ }^{11}$ Hence, serenity and spirituality are adult developmental concepts describing the essence of being human. ${ }^{2}$

Our definition of spirituality limited the concept of self-realization, but in the end, it includes other aspects, such as beliefs, connection, and trust. According to our data, this construction of identity goes with beliefs in whom you trust, with whom you agree to keep (or not) a relationship: either God, your family or the medical world. As Tuval-Mashiach and colleagues noted, in our cohort, every parent had compromised relationships with their family members, either as a cause or a consequence of living with a very sick child. ${ }^{7}$ Inevitably, this loss of family closeness becomes part of their narrative identity of the sick child's parenthood.

\section{Implication for practitioners}

Speaking medically, even when reviewing diagnostic or therapeutic plan, is always intimate for parents who are so involved in everyday care for their child. The medical caregivers are never completely neutral or objective; our own narrative identities are always present in any medical encounter. ${ }^{32}$ Some caregivers like to be listened to and respected in every suggestion; while others never want to influence parents and let the parents make every decision. But if we link these caregiving characteristics to the type of parents we have presented, an adjustment in the discussion style could be made for the benefit of the child and his/her parent. With the Almighty parents, a total obedience might not be the best attitude to promote, as the child will not be "cured," despite all the parents' efforts, and this will lead to more suffering in a long run. With the $\mathrm{Me}$ parents, clearly orienting and supporting the medical care choices could alleviate the extra stress those parents put on themselves.

\section{Implications for parents and practitioners}

Interactions with the medical world is a ubiquitous reality for parents of a child with a life-limiting medical condition. The research encounters between the researcher and the parents led to a co-construction of narrative identity for the parents. The parents read their own phenomenological story, and this could have led some parents to refine their own identity and led to self-reflection about their life with their sick child. How they interact with the health professionals could lead to a comprehension of their spiritual-narrative identity and, hence, influence the discussions to alleviate hostile or negative encounters. A useful tool for health professional caregivers is to be aware of their own spiritual identity while observing the parents' attitudes toward themselves and toward their child. ${ }^{11,33,34}$ Some parents in the Almighty category may need to be reminded that their primary role is to be the parents of their child and not their therapist. Therapists 
should be reminded that obedient parents are quite rewarding to them, but that can deter parents from their primary role of parenting love for their child. Furthermore, helping Almighty parents to remain parents despite all advice and therapies ordered is a challenge, meaning that they can make their own choices despite "therapeutic orders," as they should remain the authors of their life. Parents in the $M e$ category may need to be encouraged to reflect on the deleterious long-term effects of always wanting to take everything on their shoulders as fatigue and lifelong anxiety can be harmful to them and, therefore, to their child. The Guide parents are often the ones who "enrich" the healthcare professionals by their serenity and their search for self-realization. Caregivers and therapists should recognize the importance of their words and roles in the construction of identities and narratives of parents of a sick child. ${ }^{16}$

\section{Limitations and strengths}

Even if months separated the interviews, it is possible that the parents' serenity or suffering would change in months or years to come. Life is dynamic, and other events will challenge the identity construction with biographical oscillations and flows. ${ }^{15,35,36}$ Hence, medical encounters will always be a relationship challenge. Bias in the choice of the families is possible, but care was taken to choose objectively (upon the advice of healthcare professionals implicated in the care of the children, all unknown to the main researcher).

The strengths of this study stem from its uniqueness. Few studies have been done on the integration of spirituality in the interpretation of the relational interactions of parents-health professionals. Another strength of this study was its methodological rigour. Team analysis enabled the principal researcher to discuss iteratively with co-researchers the coding, themes, and sub-themes, leading to the emergence of a coherent, interpretative, thematic mapping. Field notes were taken and used to verify acuteness of themes revealed by the verbatim coding.

\section{Conclusions}

The goal of the study was to understand why parents' interactions with the medical world are so different, ranging from hostile to collaborative, working with the themes of identity, spirituality and serenity. Three categories emerged from the narrative interviews: i) the Almighty, delegating their power to God or medicine; they are the parents who suffer the most because they do not seem to author their own lives; ii) the $M e$, making every decision on their own causing much anxiety and becoming objectionable to the medical world; iii) the Guide, taking advice from others, while remaining the authors of their stories and being the most serene parents. Understanding and recognizing these categories can have a major impact on communication with families. Caring for very sick children is complex, but one should not set aside the importance of interpersonal skills in improving the care of these vulnerable children. Future studies are required to evaluate how improving the recognition by healthcare professionals of their own spiritual identity could led to a better future for the very sick child and their parents.

\section{References}

1. Benkel I, Molander U. A Qualitative study of the experiences of parents with an adult child who has a severe disease: existential questions will be raised. Inquiry 2017;54:46958017727107.

2. Scorgie K, Sobsey D. Transformational outcomes associated with parenting children who have disabilities. Mental Retard 2000;38:195-206.

3. Charmaz K. Loss of self: a fundamental form of suffering in the chronically ill. Sociol Health Illness 1983;5:168-95.

4. Sheikhzakaryaee N, Atashzadeh-Shoorideh F, Ahmadi F, Fani M. Psychological limbo as a barrier to spiritual care for parents of children with cancer: a qualitative study. Asian Pacific J Cancer Prev 2018;19:1063-8.

5. Nicholas DB, Barrera M, Granek L, et al. Parental spirituality in life-threatening pediatric cancer. J Psychosoc Oncol 2017;35:323-34.

6. Wilson C, Cook C. Ambiguous loss and post-traumatic growth: experiences of mothers whose school-aged children were born extremely prematurely. J Clin Nurs 2018;27: e1627-e39.

7. Tuval-Mashiach R, Hasson-Ohayon I, Ilan A. Attacks on linking: stressors and identity challenges for mothers of daughters with long lasting anorexia nervosa. Psychol Health 2014;29:613-31.

8. Gray DE. Accommodation, resistance and transcendence: three narratives of autism. Social Sci Med (1982) 2001;53: 1247-57.

9. Raines DA. Suspended mothering: women's experiences mothering an infant with a genetic anomaly identified at birth. Neonatal Network 1999;18:35-9.

10. Abdoljabbari M, Sheikhzakaryaee N, AtashzadehShoorideh F. Taking refuge in spirituality, a main strategy of parents of children with cancer: a qualitative study. Asian Pacific J Cancer Prev 2018;19:2575-80.

11. Anum J, Dasti R. Caregiver burden, spirituality, and psychological well-being of parents having children with thalassemia. J Religion Health 2016;55:941-55.

12. Sheldrake P. The New Westminster Dictionary of Christian Spirituality. Louisville: Westminster John Knox Press 2013: p. 702 .

13. Ricœur P. Time and narrative. University of Chicago Press; 1985.

14. Bury M. Chronic illness as biographical disruption. Sociol Health Illness 1982;4:167-82.

15. Castellanos MEP, Barros NF, Coelho SS. Biographical ruptures and flows in the family experience and trajectory of children with cystic fibrosis. Ciencia \& Saude Coletiva 2018;23:357-68.

16. Frank AW. The wounded storyteller: body, illness, and ethics. Second Edition: University of Chicago Press; 2013.

17. Delmar C, Bøje T, Dylmer D, et al. Achieving harmony with 
oneself: life with a chronic illness. Scandinavian J Caring Sci 2005;19:204-12.

18. Kreitzer MJ, Gross CR, Waleekhachonloet OA, et al. The brief serenity scale: a psychometric analysis of a measure of spirituality and well-being. J Holistic Nurs 2009;27:7-16.

19. Creswell JW. Qualitative inquiry and research design: choosing among five traditions. 3 ed. Thousand Oaks, California: Sage; 2017.

20. Le Breton D. L'interactionnisme symbolique. Paris cedex 14: Presses Universitaires de France; 2012: p. 256.

21. Anderson M, Tulloch-Reid MK. "How am I gonna cope?": Caregivers of adolescents with diabetes in Jamaica. Chronic Illness 2018:1742395318769373.

22. Tripkovic M, Bakija I, Sindik J, et al. Family financial situation, parental marital status and self-harm amongst adolescents in croatia. Acta Clinica Croatica 2017;56:469-77.

23. Hollway W, Jefferson T. Doing qualitative research differently: a psychosocial approach: SAGE Publications; 2012.

24. Paillé P, Mucchielli A. L'analyse qualitative en sciences humaines et sociales. Armand Colin; 2016.

25. Robinson I. Personal narratives, social careers and medical courses: analysing life trajectories in autobiographies of people with multiple sclerosis. Social Sci Med (1982) 1990;30:1173-86.

26. Nicholas DB. Meanings of Maternal caregiving: children with end stage renal disease. Qual Health Res 1999;9:468-78.

27. Meldrum ML, Tsao JC, Zeltzer LK. "I can't be what I want to be": children's narratives of chronic pain experiences and treatment outcomes. Pain Med (Malden, Mass) 2009;10: 1018-34.
28. Comte-Sponville A. L'Esprit de l'athéisme: introduction à une spiritualité sans Dieu. Albin Michel; 2009.

29. Jenner A, Scott A. Circulating beliefs, resilient metaphors and faith in biomedicine: hepatitis $\mathrm{C}$ patients and interferon combination therapy. Sociol Health Illness 2008;30:197216.

30. Curlin FA, Roach CJ, Gorawara-Bhat R, et al. When patients choose faith over medicine: physician perspectives on religiously related conflict in the medical encounter. Archives Internal Med 2005;165:88-91.

31. Kruse BG, Heinemann D, Moody L, et al. Psychometric properties of the serenity scale. J Hospice Palliative Nurs 2005;7:337-44.

32. Wilson S. 'When you have children, you're obliged to live': motherhood, chronic illness and biographical disruption. Sociol Health Illness 2007;29:610-26.

33. Arutyunyan T, Odetola F, Swieringa R, Niedner M. Religion and spiritual care in pediatric intensive care unit: parental attitudes regarding physician spiritual and religious inquiry. Am J Hospice Palliative Care 2018;35:28-33.

34. Coughlin K, Mackley A, Kwadu R, et al. Characterization of spirituality in maternal-child caregivers. J Palliat Med 2017;20:994-7.

35. Bell SL, Tyrrell J, Phoenix C. Meniere's disease and biographical disruption: Where family transitions collide. Social Sci Med (1982) 2016;166:177-85.

36. Bray L, Kirk S, Callery P. Developing biographies: the experiences of children, young people and their parents of living with a long-term condition. Sociology of Health \& Illness. 2014; 36:823-839. 